\title{
"Iniciativa Novas Oportunidades" e "NOL": dois estudos de caso no Algarve (Portugal)*
}

\author{
CATARINA DOUTOR \\ Universidade do Algarve, Faro, Portugal \\ HELENA QUINTAS \\ Universidade do Algarve, Faro, Portugal \\ CARLOS MIGUEL RIBEIRO \\ Universidade do Algarve, Faro, Portugal \\ ANTÓNIO FRAGOSO \\ Universidade do Algarve, Faro, Portugal
}

\section{RESUMO}

A "Iniciativa Novas Oportunidades" marcou a educação de adultos em Portugal ao introduzir os processos de reconhecimento e validação dos adquiridos experienciais, permitindo a certificação escolar e a qualificação profissional dos adultos. Em alguns centros de adultos foi criada a parceria Novas Oportunidades a $\operatorname{Ler}^{+}\left(\mathrm{NOL}^{+}\right)$, visando à melhoria dos níveis de literacia da população. Selecionámos dois centros como estudos de caso, com o objetivo de analisar as práticas desenvolvidas no âmbito dessa parceria. Como técnicas de recolha de informação, recorremos à análise documental e às entrevistas semiestruturadas aos diretores/coordenadores dos centros. Os resultados revelam que a iniciativa $\mathrm{NOL}^{+}$melhorou o acesso à informação e a atividades culturais, promovendo o desenvolvimento da literacia e a participação cívica. Em ambos os centros, a aprendizagem é entendida como um ato quotidiano indissociável da participação na vida coletiva. Podemos ainda concluir que as práticas de literacia, nesses casos, promoveram a conscientização no seu sentido freiriano.

\section{PALAVRAS-CHAVE}

educação e formação de adultos; processos de reconhecimento; validação e certificação de competências; literacia.

* Este trabalho foi parcialmente possível graças ao apoio da Fundação para a Ciência e a Tecnologia (FCT). 


\section{"NEW OPPORTUNITIES INITIATIVE" AND "NOL"”: TWO CASE STUDIES IN ALGARVE (PORTUGAL)}

\section{ABSTRACT}

The programme "New Opportunities" has been a bench mark within adult education in Portugal, introducing processes of recognition and validation of prior learning and experience to allow school certification and professional qualifying of the adults. In some adult centres the partnership New Opportunities to $\operatorname{Read}^{+}\left(\mathrm{NOL}^{+}\right)$was created aiming to improve the population's level of literacy. We have selected two case studies to analyse the practices developed within that partnership. We gathered information through document analysis and semi-structured interviews with the centre's directors and coordinators. Our findings show that the programme $\mathrm{NOL}^{+}$ improved the access to information and cultural activities, promoting literacy development and civic participation. In both centres, learning is understood as an everyday event associated with participation in collective life. We can further conclude that literacy practices, in those cases, promoted conscientization in its Freirian sense.

\section{KEYWORDS}

education and training of adults; recognition of prior learning processes; validation and certification skills; literacy.

\section{"NUEVAS INICIATIVA DE OPORTUNIDADES" Y "NOL": DOS ESTUDIOS DE CASO EN ALGARVE (PORTUGAL)}

\section{RESUMEN}

La "Iniciativa Nuevas Oportunidades" marcó la educación de adultos en Portugal al introducir los procesos de reconocimiento y validación de la experiencia adquirida, permitiendo la certificación escolar y la cualificación profesional de los adultos. En algunos centros de adultos se ha creado, además, el proceso "Nuevas Oportunidades a Leer"” $\left(\mathrm{NOL}^{+}\right)$, visando la mejoría de los niveles de literacia de la población. Hemos seleccionado dos estudios de caso con el objetivo de analizar las prácticas en dicho ámbito. Como técnicas de recogida de información hemos utilizado el análisis documental y entrevistas semi-estructuradas a los directores y coordinadores de los centros. Los resultados muestran que se ha mejorado el acceso a la información y a las actividades culturales, promoviéndose el desarrollo de la literacia y la participación cívica. En ambos centros, el aprendizaje es un acto cotidiano indisociable de la participación en la vida colectiva. Podemos aún concluir que las prácticas de literacia, en esos casos, han promovido la concientización en su sentido freiriano.

\section{PALABRAS CLAVE}

educación y formación para adultos; procesos de reconocimiento; validación y certificación de competencias; alfabetización. 


\section{INTRODUÇÃO}

Os baixos níveis de certificação escolar e de literacia da população portuguesa são por demais conhecidos (Benavente et al., 1996; Melo et al., 1998). Recentes medidas de política educativa têm procurado contrariar essa situação criando respostas que acelerem a qualificação académica da população portuguesa e que, ao mesmo tempo, contribuam para o aumento dos níveis de literacia. A solução preconizada pelo Estado português tem passado pela reconversão dos conhecimentos e das competências que se adquirem em diversos contextos do quotidiano, e para efetivar esses processos foram adotados sistemas de Reconhecimento, Validação e Certificação de Competências (RVCC) adquiridas ao longo da vida, mas também outros percursos que articulam educação e formação.

No panorama recente da educação de adultos em Portugal, os processos de RVCC são, assim, considerados uma estratégia-chave, "uma porta de entrada" para a requalificação académica de um elevado número de adultos detentores de baixos níveis de escolaridade, e para os efetivar foram criados os designados Centros Novas Oportunidades (CNO).

Pese embora os processos de RVCC apontarem, sobretudo, a melhoria dos níveis de certificação escolar e de qualificação profissional, também pretendem promover a continuação de percursos de educação e formação em uma perspetiva de aprendizagem ao longo da vida. Ambicionam, portanto, contribuir para uma autoformação autêntica, diversificada e reflexiva (Melo, 2011), suscitando nos adultos portugueses a curiosidade e o prazer de aprender e de saber mais. Nesse sentido, falar de trajetórias de formação contínua ao longo e ao largo da vida torna inevitável analisar práticas de literacia que devem ser encorajadas e que deverão ocorrer em simultâneo com os processos de RVCC. Provocar a perceção dessa curiosidade intelectual e, simultaneamente, a necessidade e a capacidade de a satisfazer tornou-se um imperativo dos processos de RVCC e das instituições que os promovem, os $\mathrm{CNO}$.

Este artigo apresenta e discute alguns resultados preliminares de um projeto de investigação ${ }^{1}$ cuja finalidade é conhecer a eventual "contaminação" entre experiências de reconhecimento e validação de competências e práticas de literacia por parte de adultos que passaram por processos de RVCC. Embora o projeto de investigação tome como objeto de estudo vários $\mathrm{CNO}$, os resultados que agora se apresentam reportam-se apenas aos dois centros que aderiram ao projeto "Novas Oportunidades a Ler"” $\left(\mathrm{NOL}^{+}\right)$, que pretende contribuir para a melhoria dos níveis de literacia dos adultos envolvidos em processos de RVCC. Assim, em concreto,

1 Projeto de investigação "A vida em mudança: a literacia na educação de adultos"(PTDC/ CPE-CED/105258/2008), em desenvolvimento no Centro de Investigação em Educação (CIEd) da Universidade do Minho e no Centro de Investigação sobre o Espaço e as Organizações (CIEO) da Universidade do Algarve, com financiamento de fundos nacionais, por meio da FCT/MCTES (PIDDAC) e cofinanciamento do Fundo Europeu de Desenvolvimento Regional (FEDER) por meio do COMPETE - Programa Operacional Factores de Competitividade (POFC). 
aqui iremos discutir dois dos objetivos delineados, considerando, por um lado, a importância de 1) conhecer as perceções de diretores e de coordenadores desses dois $\mathrm{CNO}$ relativamente aos processos de $\mathrm{RVCC}$ e ao projeto $\mathrm{NOL}^{+}$; e, por outro, 2) identificar e analisar as atividades que foram desenvolvidas, as quais, em uma lógica de compatibilização de ambas as iniciativas, concorreram tanto para a requalificação dos adultos como para o incremento das suas competências de literacia. A discussão desses objetivos tem também por intuito alcançar um amplo entendimento relativamente aos desafios "vividos" nos $\mathrm{CNO}$.

\section{A INICIATIVA NOVAS OPORTUNIDADES EM PORTUGAL}

Perante os baixos níveis de certificação escolar e de qualificação em Portugal, o Ministério da Educação anunciava, em 2006, a "Iniciativa Novas Oportunidades" (INO), que, por sua vez, integrava as ofertas lançadas no passado pela antiga Agência Nacional para a Educação e a Formação de Adultos (ANEFA). Enquanto oferta formativa, essa iniciativa tinha como principal finalidade contribuir para o aumento das qualificações escolares e profissionais da população adulta. Assim, à época (2006), o governo colocou em prática um conjunto de medidas que visava qualificar um milhão de adultos até 2010 (Gomes, 2012). Essas medidas apresentavam, efetivamente, um cenário inovador e metodologicamente desafiante, no qual o direito à educação destinada aos adultos adquire novos significados: valorizam-se as aprendizagens realizadas ao longo e ao largo da vida (Fragoso, 2007).

Com a queda do governo do Partido Socialista e a entrada do novo governo do Partido Social Democrata, a ANEFA foi extinta em 2002. E mais tarde, em 2007, foi criada a Agência Nacional para a Qualificação (ANQ), sob a tutela ministerial conjunta entre os ministérios do Trabalho e da Solidariedade Social e da Educação. Enquanto instituto público, a ANQ visava melhorar a qualidade da educação e formação profissional e, consequentemente, a empregabilidade e o exercício da cidadania plena. ${ }^{2}$ Em uma lógica vocacionalista, a INO acentuou as políticas e as práticas de educação de adultos orientadas para a qualificação da população adulta. De acordo com Veloso (2011), a inevitabilidade de mais e melhor qualificação tinha também o objetivo de contribuir para uma economia mais competitiva, fundamentada no conhecimento e na coesão social.

A ANQ apostou no alargamento da rede de Centros de Reconhecimento, Validação e Certificação de Competências (CRVCC), posteriormente designados de CNO. A verdade é que as iniciativas inovadoras criadas pela ANEFA sofreram uma grande mudança com a criação da INO e a criação de uma rede de CNO. No ano 2000 existiam apenas seis centros RVCC, e no final de 2006 essa rede tinha sido alargada, alcançando 274 centros (Guimarães, 2011).

Para além disso, a campanha publicitária que acompanhou o lançamento da iniciativa afigurou-se como um fator deveras influente, na medida em que divulgou em larga escala a INO e que se assentava no lema: "Novas oportunidades: apren-

2 Decreto-lei n. 276-C/2007. 
der compensa!", o que confirma o sentido de imprescindibilidade que lhe estava associado, considerando a situação débil, em termos de qualificação, que afetava a população portuguesa. Autores como Canário (2007) e Ambrósio (2007) enunciam aspetos positivos dessa iniciativa: para a população jovem, a definição de doze anos de escolarização como "patamar" e a valorização e a diversificação da dimensão profissionalizante, e, para a população adulta, a meta de qualificação de um milhão de ativos até 2010. Com a tomada de posse do governo social-democrata aliada à crise económica e política sentida em Portugal, os $\mathrm{CNO}$, e todo o processo em que estes se sustentavam, iniciaram, no final de 2011 , um ciclo de incertezas relativamente ao seu futuro, tendo o programa encerrado definitivamente no fim de março de 2013.

\section{OS CNO E OS RVCC}

De acordo com Melo (2008), no período entre 2000 e 2006, a educação e formação de adultos viveu, em Portugal, um período inédito. Os CNO desempenharam um papel insubstituível e fundamental, na medida em que validaram as aprendizagens (formais, não formais e informais) adquiridas ao longo da vida do adulto (Ambrósio, 2007). Os CNO podiam ser promovidos por entidades públicas ou privadas e tinham a missão de

assegurar a todos cidadãos maiores de 18 anos uma oportunidade de qualificação e de certificação, de nível básico ou secundário, adequada ao seu perfil e necessidades [bem como] promover a procura de novos processos de aprendizagem, de formação e de certificação por parte dos adultos com baixos níveis de qualificação escolar e profissional. (Gomes; Simões, 2007, p. 10)

Enquanto "promotores" da aprendizagem ao longo da vida, os CNO desempenharam um papel fundamental no desenvolvimento das ofertas dirigidas aos adultos (Guimarães, 2009). O processo de RVCC era desenvolvido nos centros, e suas atividades eram asseguradas por uma equipa diversificada, qualificada e especializada, que trabalhava com os adultos as diversas etapas do processo, desenvolvendo sua ação de maneira articulada. Essa equipa era constituída ${ }^{3}$ por um diretor, um coordenador, profissionais de RVC, técnicos de diagnóstico e de encaminhamento, técnicos administrativos e de apoio à gestão financeira e formadores de várias áreas. Os avaliadores externos não pertenciam às equipas permanentes, sendo seus serviços requisitados pelos centros a partir de uma bolsa de avaliadores, acreditados pela ANQ.

De forma breve, o técnico de diagnóstico e encaminhamento tinha como principal função acolher, aconselhar e encaminhar o adulto para as ofertas formativas disponíveis. Ao profissional de RVC competia o reconhecimento de competências dos adultos. Os formadores promoviam o desenvolvimento das competências dos

3 As funções da equipa do CNO encontram-se definidas na portaria n. 370/2008, de 21 de maio, Diário da República, n. 98, que regula a criação e o funcionamento desses centros. 
adultos tendo como apoio o Referencial de Competências-Chave. ${ }^{4}$ Para que o processo de RVCC fosse concluído, o adulto tinha de apresentar, perante um júri, o portfólio que, construído durante o processo, mostraria as competências adquiridas. Nesse júri participavam todos os elementos do centro (profissionais, formadores) e um avaliador externo, preponderante nessa fase. Assumindo um papel imparcial, depois de analisar o portfólio reflexivo de aprendizagens apresentado pelo candidato, podia colocar perguntas, pedir esclarecimentos ou fazer comentários.

$\mathrm{O}$ diretor representava institucionalmente o $\mathrm{CNO}$ e, sob sua orientação, o coordenador assegurava a dinamização da atividade do $\mathrm{CNO}$, sobretudo em nível pedagógico e organizacional - entre outras funções.

As atividades desenvolvidas pelos $\mathrm{CNO}$ organizavam-se em torno de seis etapas de intervenção fundamentais: acolhimento; diagnóstico; encaminhamento; reconhecimento de competências; validação de competências e certificação de competências. Os CNO apresentavam uma grande flexibilidade de práticas. Com recursos a abordagens biográficas e balanço de competências, procurava-se adequar o processo às necessidades específicas e ao ritmo de vida e aprendizagem dos adultos.

Sua dimensão de justiça social é outro aspeto positivo que era reconhecido a essa INO. A esse respeito, Carneiro (2010, p. 5) afirma que

a Iniciativa Novas Oportunidades nasceu para responder a um imperativo de justiça e de necessidade: o de mobilizar o elevado número de adultos portugueses detentores de baixas qualificações [...] para um novo modelo de oferta educativa, inovadoramente desenhado para reconhecer as competências adquiridas por via não formal e informal e para oferecer os complementos de formação indispensáveis para uma certificação formal de qualificações básicas ou secundárias e profissionais.

Pires (2006) defende que, do ponto de vista da formação de adultos, o reconhecimento das aprendizagens experienciais pode constituir-se como um motor de novas dinâmicas formativas, na medida em que contribui para a elaboração de projetos pessoais e profissionais, desenvolve a autoestima da pessoa, contribui para o reforço e a construção das identidades pessoais, sociais e profissionais, possibilitando novas oportunidades de formação. Os resultados desse processo têm, desse modo, um valor educativo, económico, social e profissional.

Contudo, essas novas práticas não deixam de ser um "terreno de tensões, de conflitualidades e de paradoxos", evidenciando a necessidade de aprofundar e refletir sobre esta prática (Canário, 2007, p. 83). O processo de RVCC, embora de inspiração humanista, não deixa de se traduzir em uma política de gestão de recursos humanos. Por outras palavras, e para Canário (idem), a educação deixa de ser entendida como um direito e passa a ser um dever do indivíduo.

4 De acordo com Alonso et al. (2002, p. 5), o Referencial de Competências-Chave propõe-se constituir uma "matriz integradora entre o balanço de competências adquiridas na experiência de vida e o desenvolvimento de projetos de educação/formação de adultos”. 
Um dos grandes mentores do sistema de RVCC, Alberto Melo (1998), sempre advertiu que o sistema não se devia massificar (o que na realidade aconteceu), devendo ser direcionado para os adultos que tivessem as competências necessárias ou que se aproximassem muito dessa situação. Melo (2011) acrescenta que o processo RVCC formatou-se como muito individualista, não se ajustando, por isso, a um processo coletivo de transformação social. Lima (2005), por seu turno, afirma que os centros sofriam uma grande pressão governamental para a produção de certificados. Corria-se o risco de conceder um certificado aos adultos, com reflexos meramente estatísticos, em detrimento da finalidade primária de melhorar sua situação diante da educação e da formação. Também Nóvoa (2007) defende que hoje, contrariamente ao passado, há uma grande tendência para a valorização da certificação e da qualificação profissional, em uma visão em que as pessoas aparecem como "ativos" ou como "recursos humanos".

Em síntese, embora as primeiras versões do sistema RVCC, entre 2001 e 2006, tenham correspondido a um modelo de reconhecimento dos adquiridos, no âmbito de um sistema educativo público em que há uma descontinuidade entre as competências das pessoas e os diplomas oficiais teoricamente correspondentes, a INO modificou as intenções do sistema. A massificação procurou resolver o problema da qualificação de recursos humanos por meio de uma lógica política, centrada nas estatísticas, e não tanto de uma formação de literacia e numeracia. Os participantes no sistema também mudaram ao longo do tempo. Inicialmente se tratava de uma maioria de adultos com grande experiência pessoal e profissional; porém, mais recentemente, o alargamento a uma população indiferenciada acabou por colocar dificuldades aos processos e colocar em causa a sua credibilidade social (Carneiro, 2010).

A verdade é que se verificaram muitas transformações no RVCC, nomeadamente as metas. Melo (2007) afirma que as metas devem ter em consideração as características dos adultos com que cada centro trabalha e do seu território de intervenção. Nessa linha de pensamento, Roberto Carneiro (2010, p. 10) refere que "as metas demasiado ambiciosas e uniformes para todos os centros não [estavam] ajustadas às realidades locais e ao contexto". Tal facto traduziu-se em um "atropelamento" das metodologias inerentes ao RVCC e, consequentemente, na progressiva desvalorização do valor social do diploma alcançado.

\section{PROJETO NOL ${ }^{+}$NOS CNO}

Lançado em setembro de 2009, o projeto $\mathrm{NOL}^{+}$resultou de uma parceria entre a ANQ e o Plano Nacional de Leitura ${ }^{5}$ (PNL). Em articulação com a Rede

5 Sendo da responsabilidade do Ministério da Educação em articulação com o Ministério da Cultura e do Gabinete do Ministro dos Assuntos Parlamentares, o PNL é uma iniciativa do governo e tem como principal objetivo aumentar os níveis de literacia da população portuguesa. Disponível em: <http://www.planonacionaldeleitura.gov.pt/ pnltv/apresentacao.php?idDoc=1>. Acesso em: 4 nov. 2013. 
de Bibliotecas Escolares (RBE), ${ }^{6}$ o principal objetivo desse projeto era apoiar o gosto pela leitura dos adultos que participavam nos processos de RVCC nos CNO. Pretendia-se, portanto, contribuir para a melhoria dos níveis de literacia da população portuguesa, tornando a leitura transversal ao processo de RVCC. O processo podia ser realizado de diversas formas e em diferentes contextos: a criação de ambientes de leitura nos CNO por meio da disponibilização de livros, revistas, jornais ou páginas de internet; a promoção de dinâmicas de leitura integradas em diversas áreas do referencial de competências-chave; o apoio e incentivos a percursos pessoais de leitura por meio da recomendação de leituras adequadas aos interesses, hábitos e competências dos adultos; a sugestão de momentos de leitura com outros membros das famílias dos adultos, implicando o aconselhamento de obras adequadas a diferentes idades; e a organização de visitas a bibliotecas públicas.

Os centros desenvolveram, ao abrigo desse programa, uma série de dinâmicas, entre as quais se destacam:

- Conto a ler: pretendia incentivar os adultos a requisitarem livros infantis e a lerem histórias às crianças do seu círculo de familiares e amigos.

- Contos da minha infância: consistia em relembrar contos e/ou histórias que os adultos ouviram enquanto crianças.

- O livro da minha vida: baseava-se na partilha de um livro que o adulto já tinha lido e do qual tivesse gostado particularmente.

- Nunca li nada de...: pretendia-se que os adultos identificassem temas ou autores de interesse, mas sobre os quais não tivessem lido nada.

- Blogue Novas Oportunidades a Ler": incentivava e, ao mesmo tempo, apoiava os adultos na construção ou enriquecimento de blogues existentes sobre livros e leitura.

- "Ler em família": propunha que os adultos lessem com as crianças de seu círculo familiar e de amigos.

- Comunidades de leitores: promovia a articulação de ações com bibliotecas escolares e/ou bibliotecas municipais (Plano Nacional de Leitura).

Essa iniciativa visava, portanto, incentivar hábitos de leitura, apoiar o processo de desenvolvimento e consolidação de competências nessa temática junto dos adultos dos $\mathrm{CNO}$, seus familiares e amigos. Tratava-se, no fundo, de fomentar uma cultura de leitura.

6 Lançado em 1996 pelos Ministérios da Educação e da Cultura, o Programa Rede de Bibliotecas Escolares (PRBE) tem como finalidade instalar e desenvolver bibliotecas em escolas públicas de todos os níveis de ensino disponibilizando, assim, os recursos necessários à leitura, ao acesso, uso e produção de informação em suporte analógico, eletrónico e digital. Disponível em: <http://rbe.min-edu.pt/np4/programa.html>. Acesso em: 4 nov. 2013. 


\section{CONTEXTO E MÉTODO}

Esse estudo fazia parte de uma investigação mais ampla desenvolvida por duas instituições de ensino superior portuguesas (Universidade do Minho e Universidade do Algarve) e teve como finalidades:

- Caracterizar as dimensões cognitivas e culturais, particularmente as práticas culturais, que os adultos traziam para os processos de RVCC.

- Compreender as formas como os adultos usavam e produziam textos durante o processo de RVCC.

- Verificar de que forma as práticas culturais e textuais em que os adultos se envolviam, durante o processo, eram posteriormente incorporadas ao seu quotidiano.

- Compreender o papel dos princípios organizativos e pedagógicos dos $\mathrm{CNO}$ na vida quotidiana dos adultos.

Neste artigo, debruçamo-nos em uma pequena parte da investigação. Temos por intuito analisar as experiências de RVCC e as práticas de literacia dos adultos que passaram por tal processo. Foram, assim, recolhidas informações com seis instituições onde se realizaram tais processos. Entre essas instituições encontravam-se escolas secundárias, associações de desenvolvimento local e o Instituto de Emprego e Formação Profissional (IEFP). Dado que a iniciativa $\mathrm{NOL}^{+}$tinha como finalidade melhorar os níveis de literacia dos adultos, pretendemos obter um entendimento mais amplo sobre as práticas de literacia dos adultos e a referida iniciativa. Iremos focar-nos apenas em duas das instituições que colocaram em prática essa iniciativa.

A recolha de informação teve como recursos essenciais a análise documental e as entrevistas semiestruturadas realizadas aos diretores/coordenadores dos dois CNO. Com a pesquisa documental foi efetuado um levantamento de informações junto dos centros de forma a efetuar sua caracterização, abarcando a candidatura técnico-pedagógica, ${ }^{7}$ o Plano Estratégico de Intervenção $(\mathrm{PEI})^{8}$ e os relatórios de atividades. ${ }^{9}$ Com as entrevistas aos diretores pretendeu-se obter informações que nos permitissem conhecer suas perceções relativamente ao processo de RVCC, bem como ao projeto $\mathrm{NOL}^{+}$. As entrevistas foram realizadas nos meses de fevereiro e março de 2011, tendo sido gravadas em áudio e posteriormente transcritas. Realizou-se uma análise de conteúdo temática (Bardin, 1997), que nos permitiu realizar um conjunto de interpretações relacionadas com a missão/objetivo(s) do centro, as metodologias utilizadas em nível organizativo e pedagógico, o papel da

7 O formulário de candidatura técnico-pedagógica é único e prende-se com os resultados relativos ao processo de encaminhamento, ao desenvolvimento do processo de RVCC e à certificação. A candidatura será analisada pela equipa da ANQ.

8 O PEI apresenta a população-alvo, as parcerias estabelecidas ou a estabelecer, a equipa técnico-pedagógica do CNO, o plano de formação, as metas e o modelo de autoavaliação.

9 O relatório de atividades refere-se às atividades desenvolvidas pelo $\mathrm{CNO}$, assim como ao seu balanço final. 
equipa técnico-pedagógica, os obstáculos sentidos durante o processo e as atividades e projetos desenvolvidos.

\section{O CNO DA ESCOLA SECUNDÁRIA DE SILVES}

O CNO da Escola Secundária de Silves foi criado no ano de 2006, com a finalidade estratégica de desenvolver a "cobertura no terreno" e dar uma resposta mais imediata às pessoas dessa área geográfica. Nesse sentido, por iniciativa própria ou por meio de parcerias estabelecidas com outras entidades, o $\mathrm{CNO}$ possibilitava aos adultos uma formação modular e cursos de educação e formação de adultos (EFA). ${ }^{10}$ Para além de atingir objetivos de certificação, esse centro pretendia contribuir para a melhoria da qualificação profissional da população ativa, para o incremento da autoestima das pessoas, bem como para a melhoria da integração da população no mercado de trabalho.

Em termos metodológicos, o coordenador do $\mathrm{CNO}$ afirmava que a equipa sentiu a necessidade de reformular suas práticas devido ao propósito de "descolarização" do processo. A equipa procurava realizar um trabalho mais reflexivo no âmbito do percurso autobiográfico dos adultos, para que pudessem evidenciar as competências que adquiriram ao longo da vida. Essa mudança de práticas justificava-se sobretudo porque esse $\mathrm{CNO}$ estava sedeado em uma escola, o que poderia induzir práticas educativas e formativas intensamente marcadas por processos formais de cariz tradicional.

Para esse coordenador, o facto de o $\mathrm{CNO}$ encontrar-se enquadrado em uma escola secundária é considerado uma vantagem, argumentando que "as pessoas vêm mais facilmente à escola porque a escola é uma instituição da comunidade [...] [a Escola Secundária de Silves] é uma referência e, [...] em termos de concelho, é a única Secundária, e isso torna-se um marco para as pessoas". Em contrapartida, o facto de o CNO encontrar-se inserido fisicamente no edifício da escola condiciona a forma como as pessoas olham para o centro. É difícil convencê-las de que o CNO não é a "escola": de facto, nesse centro não existiam "professores", mas sim "formadores"; nem “testes", mas sim a construção acompanhada de portfólios (entre outros exemplos). Contudo, o coordenador reconhece um benefício mútuo pelo facto de as duas organizações (CNO e escola) encontrarem-se no mesmo espaço físico: "a escola, e a escola acaba por beneficiar, em termos de dinâmica de inserção na sociedade da população adulta, porque a escola estava muito longe dos adultos".

$\mathrm{O}$ facto de os formadores do $\mathrm{CNO}$ serem eles próprios professores da escola, com uma visão muito escolarizada do processo de ensino e aprendizagem (frequentemente contrária aos pressupostos associados aos propósitos estabelecidos para os $\mathrm{CNO}$ ), levava o coordenador a considerá-los um obstáculo no contexto do funcionamento harmonioso da equipa: "os professores são muito tradicionais, de-

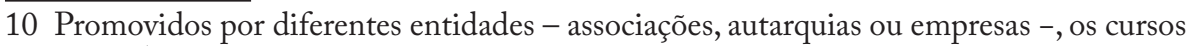
de EFA dirigem-se a adultos com idade superior ou igual a 18 anos, sem escolaridade básica, sem qualificação profissional e, de preferência, desempregados. 
masiado formais". Nesse sentido, procurou-se selecionar professores, para trabalhar na equipa, que tivessem uma atitude e uma prática educativa aberta e inovadora. Assim mesmo, seria desejável que existisse uma formação inicial mais sólida para essa equipa, sobretudo em nível avançado. Contudo, considera que as reuniões semanais que se realizam entre os elementos da equipa constituem-se como "verdadeiros momentos de formação", que vêm colmatar a deficiente formação que devia, em seu entender, ser da responsabilidade da ANQ.

No âmbito da $\mathrm{NOL}^{+}$, o CNO da Escola Secundária de Silves promoveu, durante o ano letivo 2011/2012, diversas iniciativas com o apoio da edilidade local, da Rádio Algarve FM e das bibliotecas do concelho. Entre essas iniciativas, destacam-se as seguintes:

- Criação de uma lista de livros recomendados para os referenciais de competência-chave adequada aos interesses, hábitos e competências dos adultos.

- Criação de um "cantinho da leitura" nas instalações do CNO.

- Registo do CNO no BookCrossing (posto de troca livre de livros no CNO).

- Realização de sessões de RVCC sobre o ensino básico e o ensino secundário na biblioteca da escola.

- Realização de visitas guiadas à biblioteca da escola e à sala de recursos.

- Promoção de círculos de leitura para adultos na biblioteca escolar.

O projeto $\mathrm{NOL}^{+}$era, segundo o coordenador, "muito interessante [porque] deriva de um esforço extra da equipa que [envolve] a participação ativa das profissionais [de RVC] e em especial da formadora de LC [Língua e Comunicação] que estava interessada [...] na leitura dos adultos". A equipa do CNO desenvolvia estratégias para que os adultos pudessem integrar suas experiências em atividades multiculturais. Segundo o coordenador:

Deslocamos a atividade às bibliotecas e os adultos vão lá. Muitas vezes as atividades são para adultos e crianças, em simultâneo, e para integrar no "portefólio" do adulto há lá uma parte do livro da infância. [...] Começamos com leitura e, neste momento, já temos música, cinema, pintura, exposição de fotografia [...]; tivemos, inclusive, uma sessão de leitura com massagens, para tentar associar a leitura à saúde e ao bem-estar; isso foi muito interessante e original.

Todas as atividades eram publicadas no site do $\mathrm{CNO}$, e, posteriormente, era realizado um relatório das atividades. Enquanto instrumento de divulgação e comunicação, o site era extremamente importante para divulgar à comunidade professores, adultos e seus familiares - as atividades promovidas pelo CNO. O coordenador afirma que havia a preocupação de incluir e/ou acolher os familiares e os amigos: "convidamos sempre a família e as pessoas a levarem os seus amigos $[\ldots]$ e as sessões com crianças são muito interessantes [...]; colocamos adultos a ler para crianças e crianças a ler para adultos". O projeto foi alargado a outras atividades culturais. Por exemplo, fizeram-se debates públicos sobre temas controversos, como 
a eutanásia. Importa referir a parceria com a Câmara Municipal de Silves e com o jornal regional Terra Ruiva, que publicitavam e divulgavam as atividades do CNO.

\section{O CNO DA ASSOCIAÇÃO VICENTINA}

Constituída em 1992, a Associação Vicentina é uma associação sem fins lucrativos que tem como objeto social o desenvolvimento comunitário, a formação e a melhoria das condições culturais, sociais e materiais de vida das comunidades e áreas abrangidas. Sediada em Bensafrim, a Associação Vicentina estende sua intervenção a vários concelhos e, por isso, desenvolve parcerias com entidades locais com $\mathrm{o}$ intuito de potenciar a intervenção e promover a proximidade, $\mathrm{o}$ apoio à população e a participação e animação de dinâmicas locais.

O CNO da Associação Vicentina (criado em 2006) vinha complementar a intervenção desenvolvida pela associação na área da formação e melhoria dos níveis de qualificação profissional e académica da população do território. Segundo o PEI, reconhecer, validar e certificar as competências adquiridas pelos adultos em todos os contextos de vida era a principal missão do CNO.

Contudo, a diretora do $\mathrm{CNO}$ afirmava que o $\mathrm{RVCC}$ não era só um processo para serem reconhecidas as competências adquiridas, mas que "também desencadeia uma procura [de] novas competências". Nesse sentido, e para além dos propósitos comuns que assistem aos $\mathrm{CNO}$, a estratégia de atuação desse centro era promover a igualdade, quer de género, quer na ótica melhoria do acesso de pessoas mais desfavorecidas à educação. Quanto à igualdade de género, pretendia-se propor aos candidatos em processo de RVCC o desenvolvimento reflexivo da temática no âmbito das áreas de Cidadania e Empregabilidade e Cidadania e Profissionalidade.

O CNO dispunha de uma equipa de técnicos de RVC que colaboravam de forma flexível com os adultos, em um processo que procurava valorizar suas experiências, promover a tomada de consciência dos saberes adquiridos, desenvolver a autonomia e motivar os adultos para que atingissem seus objetivos e reformulassem seus projetos de vida.

A diretora do $\mathrm{CNO}$ confessava que uma de suas preocupações iniciais foi constituir uma equipa que trabalhasse de forma colaborativa. Essa equipa técnico-pedagógica participou em todas as ações que foram oferecidas, ${ }^{11}$ embora não tantas quanto as desejadas. É de salientar que, de acordo com o PEI, a equipa gostaria de

Encontrar oferta formativa dirigida às equipas técnicas dos Centros que trabalhassem e aprofundassem competências específicas do sistema RVCC, por exemplo o trabalho da dimensão da Língua Estrangeira no processo, a exploração de competências adquiridas na história de vida, etc.

No que concerne às dificuldades sentidas no processo RVCC, segundo a diretora do $\mathrm{CNO}$, os atrasos dos financiamentos prejudicavam o trabalho da equi-

11 Formação dinamizada pelos formadores da Agência Nacional de Oficinas de Projetos, Educação e Formação (ANOP), entidade certificada em balanço de competências e formações prestadas pela ANQ ou pela própria associação. 
pa. Identificava outros obstáculos, tais como a falta de ofertas formativas para dar resposta às necessidades dos adultos e a complexidade no trabalho com os adultos, na maioria pessoas desempregadas. De acordo com a coordenadora, as metas, a equipa reduzida e o "tempo para trabalhar com as pessoas" são os principais constrangimentos dos processos de RVCC.

$\mathrm{O}$ projeto $\mathrm{NOL}^{+}$encontrava-se integrado no $\mathrm{CNO}$ da Associação Vicentina, tendo como principal objetivo apoiar os processos de desenvolvimento e consolidação de competências de leitura e escrita. Nesse âmbito, o CNO desenvolveu diversas ações, como a articulação com as bibliotecas e polos de leitura locais. Nessa iniciativa, os adultos participaram de uma sessão informativa sobre a organização e os serviços disponibilizados pela biblioteca, exploraram diferentes livros, realizaram seu cartão de leitor e requisitaram obras sobre áreas de interesse pessoal e/ou profissional.

Outras das atividades concretizaram-se na sugestão de leituras do vasto espólio bibliográfico que a associação tem vindo a adquirir ao longo dos últimos anos. No âmbito dessa atividade, os elementos da equipa do CNO realizaram um breve resumo de diversos livros, com o propósito de suscitar o interesse dos adultos. Foram ainda realizadas atividades destinadas às famílias dos adultos que procuravam o centro, tais como concursos de prosa e de poesia.

O território de ação da associação era (e é) vasto e mal equipado em nível de transportes. Esse CNO disponibilizava, assim, uma "Mala Itinerante de Livros", tornando possível sua requisição e leitura, independentemente do local onde os adultos residiam. Finalmente, foi criada uma oficina de escrita criativa. Teve como finalidade possibilitar aos adultos o contacto com as técnicas da escrita e desenvolver capacidades criadoras e literárias por meio do exercício individual e em grupo.

Perante esse conjunto alargado de atividades, a diretora do centro considerava que, em resultado da aplicação desse programa,

as pessoas redescobrem a leitura, redescobrem o prazer de estarem informadas e de ler e de conhecer. Muitas delas descobrem a biblioteca da sua terra [...] Muitas delas descobrem como é que se requisita um livro [...] Portanto as pessoas descobrem essas coisas, ou tomam consciência do prazer que isso lhes dá e que gostam de o fazer, e eu acho que é importantíssimo. Aliás, acho que isto tem sido um processo inacreditável [...] acho que se vai notar a longo prazo na população portuguesa.

Nesse sentido, acrescenta que o $\mathrm{CNO}$, nessa parceria com o $\mathrm{NOL}^{+}$, procura promover o desenvolvimento pessoal dos adultos na medida em que "lhes dá autoconfiança e autoestima, que os faz avançar e criar novos projetos de vida em função daquilo que eles já se aperceberam que eram capazes [...]. Nós valorizamos muito isso, e é sempre uma coisa que está muito presente no nosso trabalho".

\section{CONCLUSÕES}

Os dados recolhidos nos dois estudos de caso permitem-nos concluir que existe uma "contaminação" positiva entre as experiências de reconhecimento e va- 
lidação de competências e práticas de literacia por parte de adultos que passaram por processos de RVCC, e, para a consecução desse objetivo, o projeto $\mathrm{NOL}^{+}$tem contribuído de forma muito significativa. Existem, contudo, algumas reflexões conceptuais e no modus operandi dos dois CNO que estudámos e que gostaríamos de destacar.

A missão dos $\mathrm{CNO}$ em estudo consistiu em elevar os níveis de qualificação escolar e profissional da população adulta, ao reconhecer e validar os conhecimentos, as experiências e as competências adquiridas pelos adultos ao longo da vida. No caso do CNO da Escola Secundária de Silves, os dados recolhidos mostram que à missão comum são acrescentados propósitos tais como a melhoria do nível de integração da população no mercado de trabalho, sua qualificação profissional, a promoção do interesse pelo saber e, ainda, o incremento da autoestima dos adultos. A estratégia de atuação do CNO da Associação Vicentina prendia-se em promover a igualdade de género no acesso à educação.

Relativamente à dinâmica da equipa técnico-pedagógica, em ambos os $\mathrm{CNO}$, esta caracteriza-se pela flexibilidade, pela dedicação e pelo sentimento de entreajuda e de solidariedade. Em ambos os $\mathrm{CNO}$, verifica-se que o trabalho em equipa é uma realidade e que os técnicos procuram frequentar todas as oportunidades de formação que são oferecidas. Nos testemunhos recolhidos em um e no outro CNO, foi referido que as oportunidades de formação são escassas, considerando o trabalho inovador e diferenciado que os processos de RVCC requerem.

Qualquer dos CNO desenvolve parcerias com diversas entidades, nomeadamente as autarquias, as empresas privadas, as escolas, as associações, entre outros, tendo como finalidade divulgar sua missão de qualificação escolar dos adultos. De igual modo, ambos os CNO desenvolvem uma ação itinerante nos concelhos limítrofes, constituindo-se como um fator fundamental na concretização dos resultados obtidos. Quanto às dificuldades sentidas pelos $\mathrm{CNO}$, são referidos os atrasos do financiamento e a falta de ofertas formativas para os adultos tendo em conta suas necessidades.

Atenhamo-nos à parceria entre os $\mathrm{CNO}$ e o projeto $\mathrm{NOL}^{+}$. Os centros que estudámos consideram-na pertinente e declaram que se deve garantir sua continuidade na medida em que é fundamental insistir na promoção do gosto pela leitura e pela escrita entre a população adulta. Consideram-na um exemplo de boas práticas no campo da educação de adultos, uma vez que incentiva o acesso à informação e à participação cívica e apela ao desenvolvimento da literacia e de atividades culturais. Apesar de, como vimos, cada um dos centros ter encontrado e desenvolvido estratégias distintas de concretização de práticas de literacia, essas diferenças só realçam as várias possibilidades de as adequar aos locais, aos recursos e às oportunidades de que cada CNO dispõe.

De acordo com os resultados obtidos, é lícito inferir que nos centros estudados a aprendizagem é entendida e praticada como um ato quotidiano e indissociável da participação na vida coletiva e, tal como Freire (1975) defendia, os processos estão contaminados de uma dimensão crítica. A esse respeito, salienta-se a diversidade de práticas de literacia que foram aludidas, assentes e/ou estimuladoras de "dialogicidade" (idem), que suscitam e permitem uma tomada de consciência da 
realidade em que as pessoas vivem, bem como das potencialidades de provocarem transformações em seu mundo (Veloso, 2011).

Não obstante a tónica conclusiva dessa investigação quanto ao potencial de incremento de práticas de literacia no âmbito dos processos de RVCC, essa problemática encerra um conjunto de interrogações sobre as quais julgamos importante refletir. Questionamo-nos se a elevação dos níveis de escolaridade dos adultos que passam por processos de RVCC influencia positivamente suas práticas de leitura e de escrita. Interrogamo-nos sobre o impacto dessa eventual competência em outros contextos de vida dos adultos, como as práticas educativas que desenvolvem com os filhos. Em síntese, a grande questão para a qual gostávamos de ter respostas reporta para a eventual dimensão de transformação social e consequente capacidade de formar pessoas críticas, que pode advir da ativação das práticas de literacia. Cremos, desse modo, que existe um longo trabalho a desenvolver no estudo do impacto que pode ser atribuído aos processos de RVCC ao nível da mudança das mentalidades e das atitudes dos adultos que realizaram o processo.

\section{REFERÊNCIAS}

Alonso, L.; Imaginário, L.; Magalhães, J.; Barros, G.; Castro, J. M.; Osório, A.; SequeIra, F. Referencial de competências-chave. Educação e formação de adultos. Lisboa: Agência Nacional de Educação e Formação de Adultos, 2002.

Ambrósio, S. CRVCC: um Centro de Novas Oportunidades. In: Antunes, M. C. (Coord.). Educação de adultos e intervenção comunitária II. Coimbra, Edições Almedina, 2007. p. 69-84.

Bardin, L. Análise de conteúdo. Lisboa: Edições 70, 1997.

Benavente, A.; Rosa, A.; Costa, A. F.; Ávila, P. A literacia em Portugal. Resultados de uma pesquisa extensiva e monográfica. Lisboa: Fundação Calouste Gulbenkian. Conselho Nacional de Educação, 1996.

Canário, R. Multiplicar as oportunidades educativas. In: Conselho Nacional de EducAçã̃o (Org.). Aprendizagem ao longo da vida no debate nacional sobre a educação. Lisboa: CNE, 2007. p. 167-173.

Carneiro, R. (Coord.) Resultados 2010 da Avaliação Externa da Iniciativa Novas Oportunidades. Lisboa: Universidade Católica Portuguesa, 2010. Disponível em: < http:// educar.files.wordpress.com/2010/10/9604.pdf>. Acesso em: 10 set. 2013.

Fragoso, A. As novas oportunidades em contexto de educação de adultos: qualificação ou certificação? In: Conselho NACional de Educação (Ed.). Aprendizagem ao longo da vida no debate nacional sobre educação. Lisboa: CNE, 2007. p. 201-213.

Freire, P. Pedagogia do oprimido. 2. ed. Porto: Afrontamento, 1975.

Gomes, M. C.; Simões, F. Carta de qualidade dos Centros Novas Oportunidades. Lisboa: ANQ, 2007.

Qualificar adultos em Portugal: políticas públicas e dinâmicas sociais. 2012. Tese (Doutoramento em Sociologia) - ISCTE, Instituto Universitario de Lisboa, Lisboa 2012. 
Guimarães, P. Políticas públicas de educação de adultos em Portugal: diversos sentidos para o direito à educação? Rizoma Freireano: educación, ciudadania y democracia, Xàtiva (Espanha): Instituto Paulo Freire de España,v. 3, [online], 2009. Disponível em: <www. rizoma-freireano.org/index.php/politicas-publicas>. Acesso em: 28 maio 2015.

Políticas de Educação de Adultos em Portugal (1999-2006). A emergência da educação e formação para a competitividade. Braga: Universidade e do Minho; Instituto de Educação, 2011.

Lima, L. A educação de adultos em Portugal (1974-2004): entre as lógicas da educação popular e da gestão de recursos humanos. In: CanÁrio, R.; Cabrito, B. (Orgs.). Educação e formação de adultos. Mutações e convergências. Lisboa: Educa, 2005. p. 31-60. Melo, A. Reconhecimento, validação e certificação de competências adquiridas. In: Conselho Nacional de Educação. Aprendizagem ao longo da vida no debate nacional de educação. Lisboa: Conselho Nacional de Educação (CNE); Ministério da Educação, 2007. p. 193-200.

A Nova Educação-Formação de Adultos em Portugal pede uma organização nova. Direito de Aprender, 2008. Disponível em: <http://www.direitodeaprender.com. pt/index2.php?option=com_content\&do_pdf=1\&id=232>. Acesso em: 25 out. 2011.

Ceci n'est pas une préface. In: Barros, R. (Ed.). A criação do Reconhecimento de Adquiridos Experienciais (RVCC) em Portugal: uma etnografia crítica em educação de adultos. Lisboa: Chiado Editora, 2011. p. 13-23.

.; Queirós, A. M.; Silva, A. S.; Salgado, L.; Rothes, L.; Ribeiro, M. Uma aposta educativa na participação de todos: documento de estratégia para o desenvolvimento da educação de adultos. Lisboa: Ministério da Educação, Secretaria de Estado da Educação e da Inovação, 1998. (Coleção Educação para o Futuro)

NóvoA,A.É preciso manter uma vigilância crítica sobre o reconhecimento de adquiridos. In: Conselho Nacional de Educação. Aprendizagem ao longo da vida no debate nacional de educação. Lisboa: CNE; Ministério da Educação, n. 7, p. 10-18, set. 2007.

Pires, A. L. Complexité de la reconnaissance des acquis et éducation/formation. In: Anais Educação e Desenvolvimento 2005. Lisboa: Unidade de Investigação Educação e Desenvolvimento (UIED), 2006. p. 81-88.

Portugal. Ministério da Educação. Decreto-lei n.276-C/2007, de 31 de julho de 2007. Diário da República, Ministério da Educação, I Série, n. 146, 3o suplemento, 31 jul. 2007. Disponível em: <http://www.dges.mctes.pt/NR/rdonlyres/90DBE647-5CB64846-B88F-101180D9E425/5043/DL276C_2007.pdf >. Acesso em: 9 set. 2013.

Portugal. Ministério do Trabalho e da Solidariedade Social e da Educação. Portaria n. 370/2008, de 21 de maio 2008. Diário da República, Série I, n. 98, 21 maio 2008. Disponível em: <http://www.dgaep.gov.pt/upload/Legis/2008_portaria_370_21_05. pdf $>$. Acesso em: 9 set. 2013.

Veloso, E. Vidas depois da reforma. Políticas públicas no contexto português e práticas educativas numa Universidade da Terceira Idade em Portugal. Lisboa: Coisas de Ler Edições, 2011. 


\section{SOBRE OS AUTORES}

Catarina Doutor é mestre em educação social pela Universidade do Algarve (Portugal).

E-mail: cdoutor@ualg.pt

Helena Quintas é doutora em ciências da educação pela Universidade do Algarve (Portugal). Professora auxiliar da mesma instituição.

E-mail:hquintas@ualg.pt

Carlos Miguel Ribeiro é doutor em didática da matemática pela Universidad de Huelva (Espanha). Professor adjunto da Universidade do Algarve (Portugal).

E-mail: cmribeiro@ualg.pt

António Fragoso é doutor em pedagogia pela Universidad de Sevilla (Espanha). Professor adjunto da Universidade do Algarve (Portugal).

E-mail: aalmeida@ualg.pt

Recebido em dezembro de 2013

Aprovado em outubro de 2014 